\title{
THE INVESTIGATION OF STIFFNESS OF HYBRID BISTEEL I-SECTION BEAMS
}

\author{
Arūnas JARAS* \\ Department of Applied Mechanics, Faculty of Civil Engineering, \\ Vilnius Gediminas Technical University, Vilnius, Lithuania
}

Received 02 June 2021; accepted 14 June 2021

\begin{abstract}
The stiffness analysis of the simple supported hybrid bisteel I-section beam subjected by uniformly distributed load is considered in this paper. The hybrid bisteel I-section beam presents a composition of high-strength steel inclusions for the flanges in the region of maximum stresses and of low-strength steel for remaining volume of the beam. The explicit analytical model for evaluation of stiffness of the beams mentioned is presented. The geometrical linear approach and elastic plastic material model have been assumed. The application of high-strength steel inclusion in case perfectly elastic state of the hybrid bisteel I-section beam, increase the deflection insignificantly (up to $10 \%$ ). While strain hardening effect reduces the deflection by about 4 times compared to the perfect plasticity. The verification of the theoretical analysis has been performed by the FEM. After simple transformations, the proposed model can be easily applied to the evaluation of stiffness of otherwise loaded and supported hybrid bisteel I-section beams.
\end{abstract}

Keywords: hybrid bisteel I-section beam, high strength steel inclusions, stiffness analysis.

\section{Introduction}

Many years the engineering norm in design of steel structures have been a monosteel structures, made from mild carbon steel. The reference literature show, that development of steel structures has shifted towards the use of high-strength steels in various building structures and beyond (Dowling \& Burgan, 1998; Owens \& Wood, 1998; Kvedaras et al., 1998). The high strength steels are widely used in North America and Japan, but in Europe, hybrid steel structures are not widespread in construction and have not been sufficiently investigated (Veljkovic \& Johansson, 2004).

Nowadays interest in higher strength steels (HSS) has emerged as a result of the successful employment of this type of steel in advanced applications within modern structures. As might be expected, the main argument for the application of hybrid steel structures is the economic effect, obtained in comparison with analogous homogeneous structural solutions.

The development and application of HSS in construction brought the ability to increase safety margin, reducing the cross-sectional dimensions, as well as weight and cost of the entire structure (Earls, 1999; Belenia et al., 1986; Handbook of steel structures, 1989; Tshernov et al., 1992;
Gorev et al., 1997). Therefore, the hybrid bisteel structures with HSS may be considered an important area of future development.

The application of HSS to strengthen I-section beams may be realized in variety of ways: composition of hybrid bisteel I-section beams (HBB) inserting the HSS section in the region of maximum moments (Shokouhian \& Gupta, 2015; Belenia et al., 1986); using cover plates (built-up technique) consisting in strengthening flanges (Ju et al., 2020; Belenia et al. 1986), construction of bisteel beams fabricated by using a HSS in the entire flanges (Veljkovic \& Johansson, 2004; Belenia et al., 1986; Handbook of steel structures, 1989); the arrangement of HSS inclusions for the flanges in the region of maximum stresses (Belenia et al., 1986; Jaras \& Kačianauskas, 2001, 2002).

Covering the investigation of above mentioned hybrid bisteel beams, other studies related to HBB are also being addressed. Here need to be mentioned the scientific researches: on optimization of the HBB, discussed in Alekseytsev and Al Ali (2018), on investigation of the behavior of hybrid steel beams with closely spaced web openings (Bhat \& Gupta, 2021), and trapezoidal corrugated-web (Elamary et al., 2021), on analysis of moment-shear in-

*Corresponding author. E-mail: arunas.jaras@vilniustech.lt 
teraction of $\mathrm{HBB}$ at ambient and elevated temperatures (Ghadami \& Broujerdian, 2019) and other.

It should be noted, that design of hybrid bisteel beams is not directly addressed in the current design codes. In some countries they are not permissible, or their design is an internal matter of each country.

This paper is aimed to develop the explicit analytical model for the stiffness analysis in the case of elasticplastic strain hardening simply supported hybrid bisteel I-section beams, subjected to uniformly distributed quasistatic load. Moreover, the model proposed may be simply transformed to be applied to other types of beams under different loading.

\section{Geometry and material model}

The hybrid bisteel I-section beam (HBB) considered, presents a composition of higher-strength steel (HSS) inclusions for the flanges in the region of maximum stresses and of lower-strength steel (LSS) for the remaining volume of the beam. The constant cross-section beam is simply supported and subjected to uniformly distributed quasi-static load (see Figure 1a).

In the framework of the present investigation geometrically linear two-dimensional bending beam is considered as slender beam based on Bernoulli hypothesis about straight and undeformed section. The hypothesis of small displacements and strains, as well as the elastic-plastic linear hardening material model are assumed. Since the deformations caused by shear stresses are neglected, therefore, one-dimensional stress-strain state, defined by normal stress $\sigma$ and strain $\varepsilon$, remains.

The geometry of the beam is described by span length $l$, cross-section height $h$, the geometry of flanges is defined by $b_{f}$ and $t_{f}$ while the geometry of web is given by dimensions $h_{w}$ and $t_{w}$ (see Figure 1b). According to distribution of maximal bending moments, the flange inclusions are embedded in the middle of the beam and are defined by the length $l_{\text {inc }}$.

The elastic-plastic linearly strain hardening material model assumed, of both HSS flange inclusions and LSS of the remaining volume of the beam are defined by a bilinear stress-strain relation (see Figure 2).

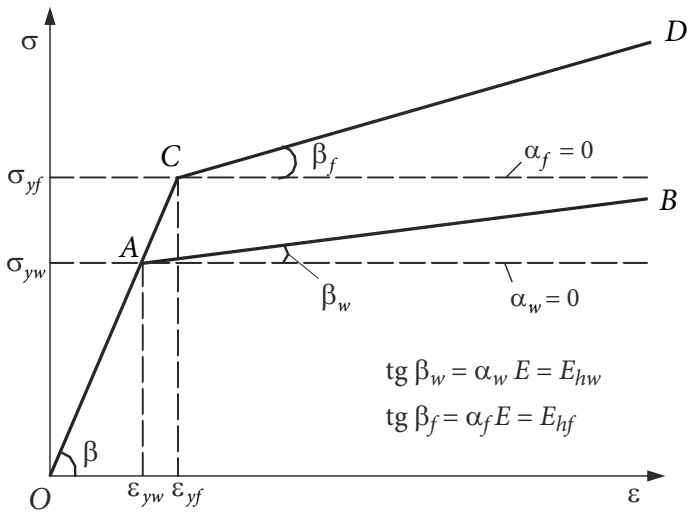

Figure 2. The stress-strain diagram of HS and LS steels

Here the elastic branches $O A$ and $O C$ are described by Hook's law $\sigma=E \varepsilon$, while plastic branches $A B$ and $C D$, by linear relationships, respectively:

$$
\begin{aligned}
& \sigma_{w}=\sigma_{y w}+\alpha_{w} E\left(\varepsilon_{w}-\varepsilon_{y w}\right) ; \\
& \sigma_{f}=\sigma_{y f}+\alpha_{f} E\left(\varepsilon_{f}-\varepsilon_{y f}\right) .
\end{aligned}
$$

According to current design codes (STR-2.05.05:2005 (LR Aplinkos ministerija, 2005)) the modulus of elasticity are equal $E_{w}=E_{f}=E$. While the strain hardening factors are described $\alpha_{w}=E_{h w} / E, \alpha_{f}=E_{h f} / E$ respectively.

A general yielding model at hybrid bisteel I-section provides four different stress regions with two elastic cores in the flanges $a_{f}$ and in the web $a_{w}$ and two plastic zones in the flanges and in the web respectively (Figure 1a, 1c). Stresses in plastic regions composed of two addends corresponding to perfect plasticity and strain hardening. This analytical model assumes that plastic zones lay inside the range of HSS flange inclusions. Plastic zones are limited by prescribed value of elastic core in the web $a_{0}$, where $a_{w} \geq a_{0}$.

It should be noted, that inelastic behaviour of steel strongly affects to the stiffness of structure investigated. Therefore the evaluation of the depth and longitudinal distribution of plastic zones, according to different yielding models (yielding on the web, flanges, or both), presented in Figure 1c, is essential in stiffness analysis. The evalu- a)

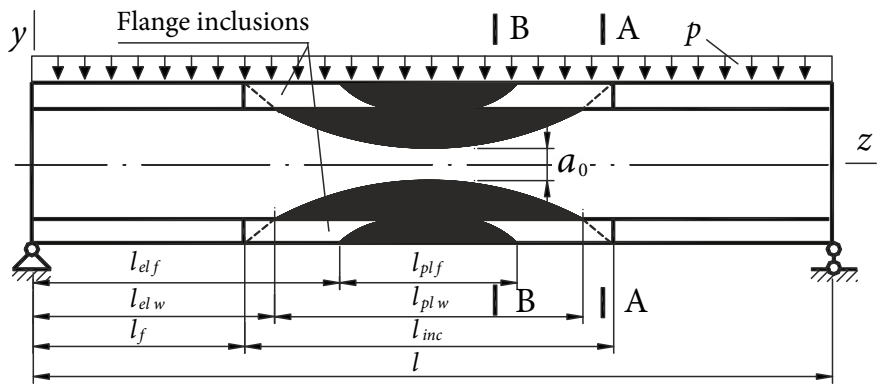

b)

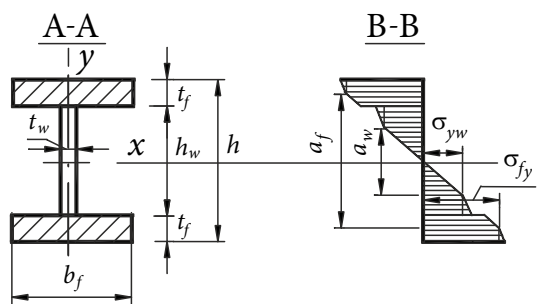

Figure 1. Hybrid bisteel I section beam: a - general view and principal distribution of plastic zones; $\mathrm{b}$ - cross section; $\mathrm{c}$ - penetration of plastic strains at cross section 
ation the geometry of plastic zones (in considered case shaped by parabola) of the entire hybrid bisteel I-section beam, expressed in term of non-dimensional elastic core $\bar{a}=\bar{a}(z)$, can be obtained by solving cubic equation (Jaras \& Kačianauskas, 2002):

$$
A \bar{a}^{3}+B(\bar{z}) \bar{a}+C=0
$$

where the coefficients are expressed as $B(\bar{z})=B_{1}(\bar{z})-B_{2}$. The coordinate dependent coefficient $B_{1}(\bar{z})$ is expressed as:

$$
B_{1}(\bar{z})=-\frac{6 p}{\sigma_{y w} t_{w}}\left(\bar{z}-\bar{z}^{2}\right) .
$$

Constant coefficients $A$ and $B_{2}$ may be presented as follows:

$$
\begin{aligned}
& A=1+\frac{\bar{b}_{f} s^{3}}{\bar{t}_{w}}-\alpha_{w}-\alpha_{w} \frac{\bar{b}_{f} s^{3}}{\bar{t}_{w}} \\
& B_{2}=3 \bar{h}_{w}^{2}+\frac{12 s \bar{b}_{f}}{\bar{t}_{w}}\left(\frac{\bar{h}_{w}}{2}+\bar{t}_{f}\right)^{2}- \\
& a_{w} 3 \bar{h}_{w}^{2}-\frac{a_{f} 12 s \bar{b}_{f}}{\bar{t}_{w}}\left(\frac{\bar{h}_{w}}{2}+\bar{t}_{f}\right)^{2} .
\end{aligned}
$$

The free member may by presented as $C=C_{1}+C_{2}$, where:

$$
C_{1}=\frac{2 \bar{b}_{f}}{\bar{t}_{w}} \bar{h}_{w}^{3},
$$

while $C_{2}$ depends on the yielding case. Generally:

$$
C_{2}=-a_{w} 2 \bar{h}_{w}^{3}-\frac{a_{f} 16 \bar{b}_{f}}{\bar{t}_{w}}\left(\frac{\bar{h}_{w}}{2}+\bar{t}_{f}\right)^{3} \text {. }
$$

The solution of equation (3) obtained using computer algebra software is presented in form:

$$
\bar{a}_{w}(\bar{z})=\frac{D}{3 A}-\frac{B(\bar{z})}{D},
$$

where:

$$
D=\left(\frac{1}{2}\left(-27 A^{2} C+\sqrt{108 A^{3} B(\bar{z})^{3}+729 A^{4} C^{2}}\right)\right)^{1 / 3} \text {. }
$$

For different yielding models, the corresponding addends turn to zero and the coefficients $A, B, C, D$ acquire more simple expressions. In the case of perfect plasticity with $\alpha_{w}=\alpha_{f}=0$, in particular, the algebraic equation (3) takes a quadratic form (Jaras \& Kačianauskas, 2002).

The explicit solution (9) may be applied for evaluating the length of plastic zones as it is illustrated in Figure 1a. The length of flange inclusions may be obtained in the same way. Finally, it may be expressed in terms of external load:

$$
l_{i n c}=l \sqrt{1-p_{e l} / p} .
$$

Variation of HSS flange inclusions properties is defined by inhomogeneity ratio $s$, which is defined as the ratio of yielding stresses of the HSS inclusions and remained steel (LSS) $s=\sigma_{y f} / \sigma_{y w} \geq 1$. Based on yielding model analyzed, in previous research performed by authors (Jaras \&
Kačianauskas, 2002) for the case of short inclusions, approximately $l_{i n c} \leq 0.6 l$, it is limited by the average inhomogeneity ratio $s \leq 1.6$. For higher ratios $s>1.6$, the yielding starts to split into two regions, therefore, this investigation is restricted by $s \leq 1.6$.

\section{The analytical model of stiffness analysis}

In many applications of beams, the stiffness parameters rather than the stress in the outer fibbers may limit the maximum load that can be permitted to be applied to the beam. Particularly, stiffness requirements are much more important if the beam is strained inelastic. In engineering practice, the stiffness of structures is regulated by applicable design codes (European Committee for Standardization, 2005; LR Aplinkos ministerija, 2005). Generally the stiffness constraints can be expressed in general inequality:

$$
f_{s}(u) \leq f_{s, \text { lim }},
$$

where: $f_{s}$ - restriction function, $f_{s, l i m}$ - limiting restriction factors, $u$ - vector of stiffness factor.

The deflection, slope and curvature of the entire HBB with their maximum values, are the stiffness parameters under consideration. All the assumptions of the beam theory discussed above apply here, the load does not exceed the load carrying capacity, and the depth of the plastic zones and the properties of the inclusions do not exceed the previously established limits of validity of the analytical model.

In order to develop the simple engineering friendly modelling tool, the principle of virtual work and Mohr's moments-area integrals are applied. Since the influence of shear stresses is neglected, the following integrals for the slender beam may be applied for the evaluation of the deflection and slope respectively:

$$
\begin{aligned}
& u(z)=\int_{0}^{l} \frac{M_{1 f}(z) M(z)}{K(z)} ; \\
& \varphi(z)=\int_{0}^{l} \frac{M_{1 m}(z) M(z)}{K(z)},
\end{aligned}
$$

where $M_{1 f}(z), M_{1 m}(z)$, are the bending moments of any section of the beam, caused by dummy load (or moment) of unity respectively. In this case $M(z)$ is the bending moment caused by external load, while $K(z)$ is the bending stiffness. Actually, ratio $M(z) / K(z)$. expresses the curvature of the beam $\chi(z)$. Since Bernoulli's law is valid, the plastic curvature for symmetric cross section may also be expressed in terms of curvature and the elastic core:

$$
\frac{M(z)}{K(z)}=\frac{M_{e l}(z) \bar{h}}{K_{e l}(z)^{\bar{a}_{w}}(\bar{z})},
$$

where, the stiffness is controlled by the limit of elastic core $\bar{a}_{w}(z)$ which may be easily evaluated by using (9).

Development of analytical model is mainly focused to evaluation of load-dependent stiffness $K(z)$ by integration within individual layers $i$ : 


$$
K(z)=\sum_{i=1}^{m} E_{p l i} t_{w i} \int_{h_{i}(z)}^{h_{i+1}(z)} y^{2} d y
$$

where the height of layer $h_{i}\left(a_{i}(z)\right)$ may depend of values of plastic zones $a_{i}$. The elastic-plastic modulus, for associated plasticity, may be expressed as:

$E_{p l}=E-E\left\{\frac{\delta f}{\delta \sigma}\right\}\left[A+\left\{\frac{\delta f}{\delta \sigma}\right\}^{T} E\left\{\frac{\delta f}{\delta \sigma}\right\}\right]^{-1} \cdot\left\{\frac{\delta f}{\delta \sigma}\right\}^{T} E$,

where $f$ - yield function, $\{\sigma\}$ - stress vector, $A$ - hardening-dependent parameter. Finally, after mathematical simplifications, the elastic plastic modulus (17) may be expressed in term of inhomogeneity ratio:

$$
E_{p l}=E \frac{s}{s+1} \text {. }
$$

Generally, by substituting (15) into (13-14) the above integrals take the form as follows:

$$
\begin{aligned}
& u(z)=\sum_{i=0}^{n} \int_{0}^{l_{n}} M_{1 f}(z) \frac{M_{e l}(z) \bar{h}}{K_{e l}(z) \bar{a}_{w}(\bar{z})} d z ; \\
& \varphi(z)=\sum_{i=0}^{n} \int_{0}^{l_{n}} M_{1 m}(z) \frac{M_{e l}(z) \bar{h}}{K_{e l}(z) \bar{a}_{w}(\bar{z})} d z .
\end{aligned}
$$

Actually, each of these integrals contains $n$ separate addends which reflect the influence of perfectly elastic and elastic-plastic zones of entire beam. Here, the elastic term can be evaluated explicitly, while the computation of elastic-plastic terms requires numerical approximation.

Finally, after performing the integration of (19) the midspan deflection $u_{\max }$ obtained by computer algebra may be presented explicitly by using at least four point Gauss quadrature:

$$
\begin{aligned}
& u_{\max }=\frac{p z_{e l w}^{3}}{12 K_{e l}}\left(2 l-\frac{3 z_{e l w}}{2}\right)+ \\
& \sum_{i=1}^{n} H_{i} \frac{l / 2}{6 K_{e l}} z_{i}\left(\frac{-B(z)}{A}+\frac{\sqrt[3]{2}(B(z))^{2}}{A G}+\frac{G}{\sqrt[3]{2} A}\right),
\end{aligned}
$$

where

$$
\begin{aligned}
& G=\sqrt[3]{-27 A^{2} C-2(B(z))^{3}+H} \\
& H=\sqrt{-4(B(z))^{6}+\left(-27 A^{2} C-2(B(z))^{3}\right)^{2}},
\end{aligned}
$$

while $A, B, C$ are already defined by (4-8).

For practical reason, the stiffness problem $u(z) \leq u_{\max }$ may by reduced to dimensionless deflection parameter of midspan, with $z=l / 2$ :

$$
\bar{u}_{\max } \frac{u_{\max } p}{\sigma_{y w} l^{2}} .
$$

For the case of perfect plasticity, where $\alpha=0$, the midspan deflection (21) transforms to already known expression (Jaras \& Kačianauskas, 2001).

\section{Illustration of analytical models and results}

The developed stiffness analysis model (13-24) is implemented into simple program codes, while the analysis results illustrate the validity of models as well as their applicability in engineering design.

In order to avoid the local instabilities, the dimensions of cross-sections are fixed according to standard steel shapes. The I-section HBB of length $l=1.0 \mathrm{~m}$, non-dimensional height $\bar{h}=h / l=0.12$ and the remaining standard proportions $\bar{h}_{w}=h_{w} / h=0.8783, \bar{t}_{w}=t_{w} / h=0.040$, $\bar{b}_{w}=b_{w} / h=0.533, \bar{t}_{f}=t_{w} / h=0.0608$ are considered as an illustrative example. The hardening ratio for both steel grades considered here, is expressed by single parameter $\alpha=\alpha_{w}=\alpha_{f}$.

It should be noted, that the effect of HSS inclusions, is more significant, if plastic deformation occurs. Here for the sake of convenience, the elastic core $a_{w}$ is converted to the depth of plastic penetration: $\bar{c}_{0}=\left(h-a_{w}\right) / h$. The influence of HSS inclusions is expressed in term of inhomogeneity ratio $s$.

The results obtained in previous research performed by authors (Jaras \& Kačianauskas, 2002) show the validity of the yielding model analyzed, for the case of short inclusions, approximately $l_{i n c} \leq 0.6 \mathrm{l}$, which is limited by the average inhomogeneity ratio $s \leq 1.6$. For higher ratios $s>1.6$, the yielding starts to split into two regions, therefore, this investigation is restricted by $s \leq 1.6$.

The stiffness analysis illustrates variations of deflection and curvature of HBB. Changes of stiffness may be considered by longitudinal variation curvature $\chi(z)$. A comparison of curvature curves for elastic monosteel and $\mathrm{HBB}(l=$ $1.0 \mathrm{~m}$ ) is presented in Figure 3. Monosteel beam is characterized by dimensionless capacity moment $\bar{M}_{c 0}=0.0332$. Stiffness properties of HBB with $s=1.4$ corresponds to $\bar{M}_{c 0}=0.0377$ for elastic case and $\bar{M}_{c 0}=0.0521$ for plastic case. Hardening model provides plastic penetration $\bar{c}_{0}=0.541$, while perfect plastic model $-\bar{c}_{0}=0.780$, which leads to sharp changes in slope and is similar to plastic hinge model.

While the longitudinal variation of relative deflections $(l=6.0 \mathrm{~m})$ when the plastic penetration occurs in the wall and the HSS flanges both is presented in Figure 4.

The diagrams shows, that at perfect plasticity, the deflection starts to grow drastically as the plastic hinge begins to form in the most critical (middle) section, while strain hardening effect reduces the deflection by about 4 times compared to the perfect plasticity.

In order to get a more detailed impact of the influence of HSS inclusions on the stiffness of the hybrid bisteel beams, the relationship study between the main stiffness indicator - the midspan deflection - and the inhomogeneity ratio $(s)$ was conducted and presented in Figure 5.

The curves were formed by applying fixed relative depths of plastic penetration $\bar{c}_{0}=0.627, \bar{c}_{0}=0.441$, $\bar{c}_{0}=0.252$. Each point was calculated at different loads, corresponding to such a plastic zone. The values of the inhomogeneity ratio $s=1.0$ correspond to a monosteel 
beam. The graphs show the increase in deflection compared to a perfectly elastic monosteel beam whose deflection $\bar{u}=0.087 \cdot 10^{-6}$ is plotted in a dotted line. At the relative depth of plastic penetration in the mid-section $\bar{c}_{0}=0.441, \bar{c}_{0}=0.252$ decrease in deflections is observed by increasing the yield strength of the inclusions. This can be explained by the nature of plastic deformations. At lower inhomogeneity ratios $s$, a given depth of plastic penetration is achieved by yielding both the web and the flanges, while increasing $s$, the plastic deformations does not occur in the flanges. In case larger plastic penetration in the cross-section, as shown by the curve $\overline{c_{0}}=0.627$, the flanges are under yielding conditions all the time and proportional increase in deflections is observed, even by increasing strength of the inclusions. By increasing the permissible depth of the plastic penetration $\bar{c}_{0}$, the state of the most critical section of the beam is close to the plastic hinge and the deflections increase drastically.

As common, the stiffness of structures is usually illustrated by a load-deflection diagram. The load-deflection diagrams of the hybrid bisteel I-section beam, illustrating the relationship between the midspan deflection and the external loading at various values of the inhomogeneity ratio $(s)$ are presented in Figure 6.

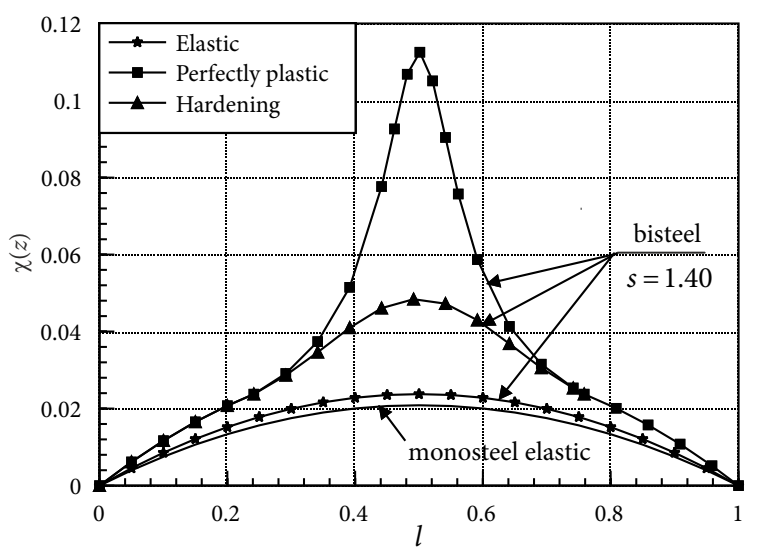

Figure 3. The HBB curvature diagram

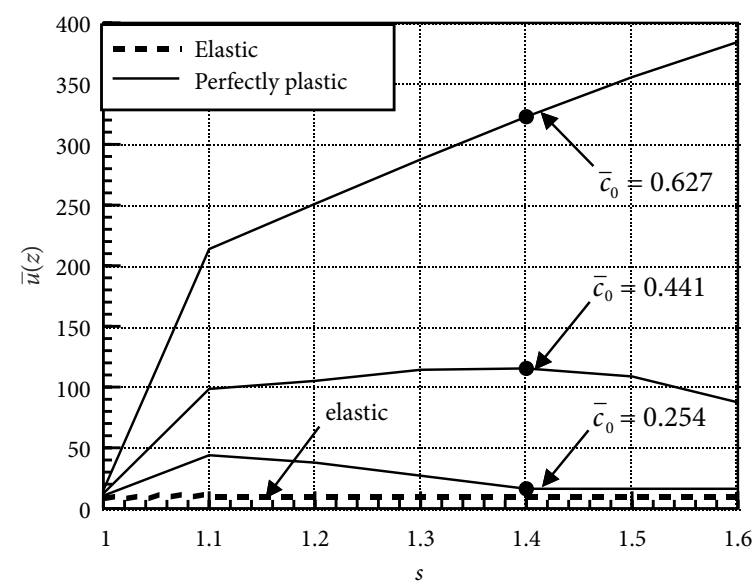

Figure 5. Variation of midspan deflection due to inhomogeneity ratio $s$ and relative depth of plastic penetration $\bar{c}_{0}$
They allow us to state about significant changes in stiffness in case of plastic behavior of the flanges. While plastic penetration grow only in the web, the deflection growth is relatively very small and the structure is able to accept a relatively large load increment. But the horizontal lines shows the vanishing of the elastic zones in the flanges inclusions and the subsequent drastic deflection growth with almost no load increase.

The study confirmed the likely practice that the higher ratio of steel strength of flange inclusions and the remaining steel (higher inhomogeneity ratio $s$ ) improve not only the strength but also the stiffness of the structure considerate.

\section{Numerical analysis by FEM}

For the sake of verification of the analytical model for stiffness analysis, the numerical experiment using FEM based commercial package ANSYS was performed (ANSYS, 2019). During the study, the 3D numerical model was meshed by tetrahedral-shaped ten-node SOLID-92 type finite elements with three degrees of freedom in each node. The meshed model is presented in Figure 7.

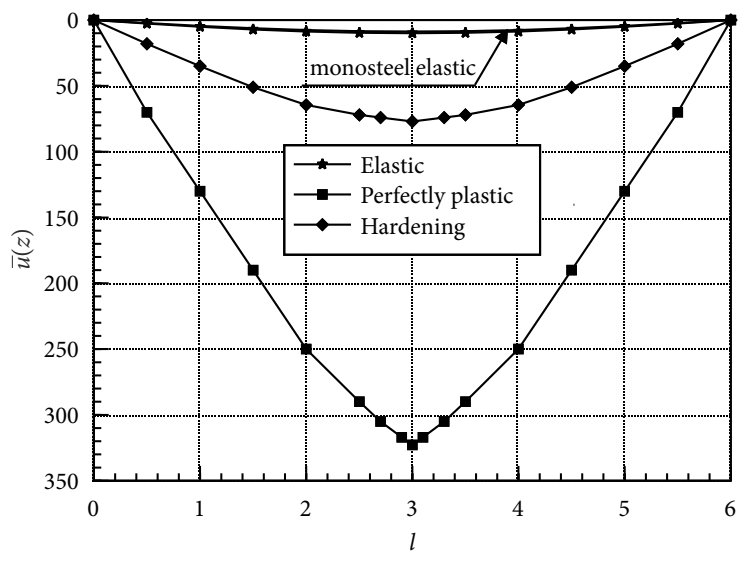

Figure 4. The longitudinal variation of deflections

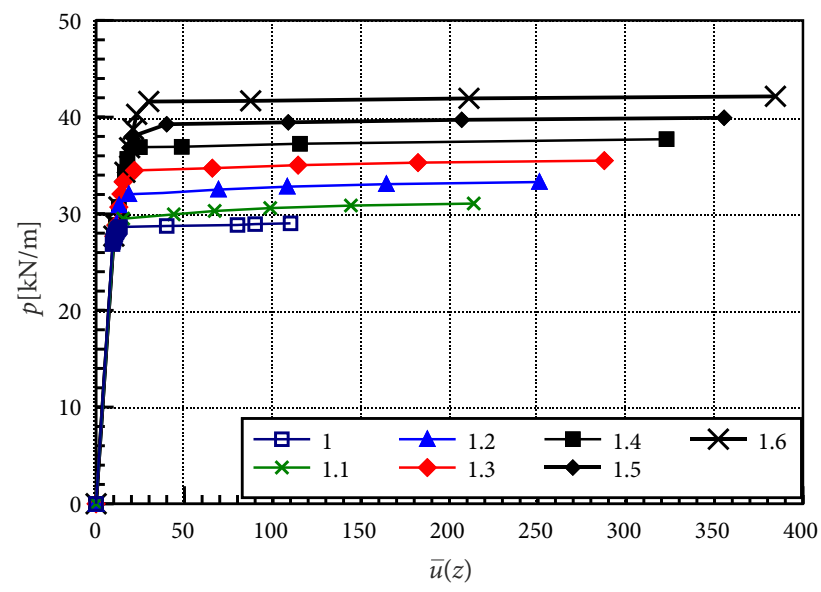

Figure 6. The load - deflection diagram 


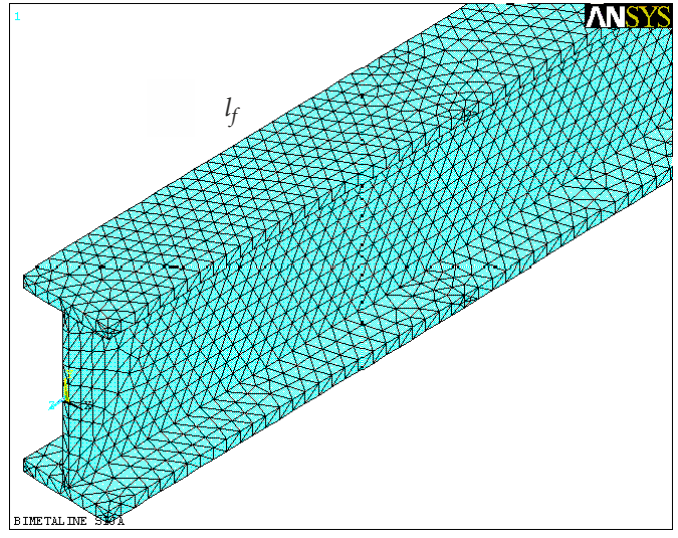

Figure 7. FEM model of the I-section HBB

In order to avoid the local instabilities, the dimensions of cross-sections are fixed according to standard steel shapes. A numerical analysis of the stiffness was performed on a bisteel I-section beam of length $l=6.0 \mathrm{~m}$, height $h=0.05 l$ and remaining dimensions $h_{w}=0.932 h, t_{w}=$ $0.02167 h, b_{f}=0.450 h, t_{f}=0.034 h$. At the inhomogeneity ratio $s=1.4$ the bisteel beam was uploaded by uniformly distributed loads $p=34.3 \mathrm{kN} / \mathrm{m}$ and $p=37.7 \mathrm{kN} / \mathrm{m}$. These loads corresponds to the two typical cases of the plastic penetration in a bisteel I-section beams, presented in analytical model, when the plastic zones penetrate only in the wall and when both the wall and the higher-strength steel flanges flow.

In addition, as the results of the load carrying capacity show, under these conditions there is no doubt about the applicability of the model in global analysis of bisteel beams, including stiffness analysis. Because the validation of the analytical model in terms of load carrying capacity is limited by the length of the HSS inclusions $\left(l_{\text {inc }} \leq 0.6 l\right)$ (Jaras \& Kačianauskas 2001).

The results obtained show that the deformed shape (elastic-plastic nature) is the same in both typical cases

a)

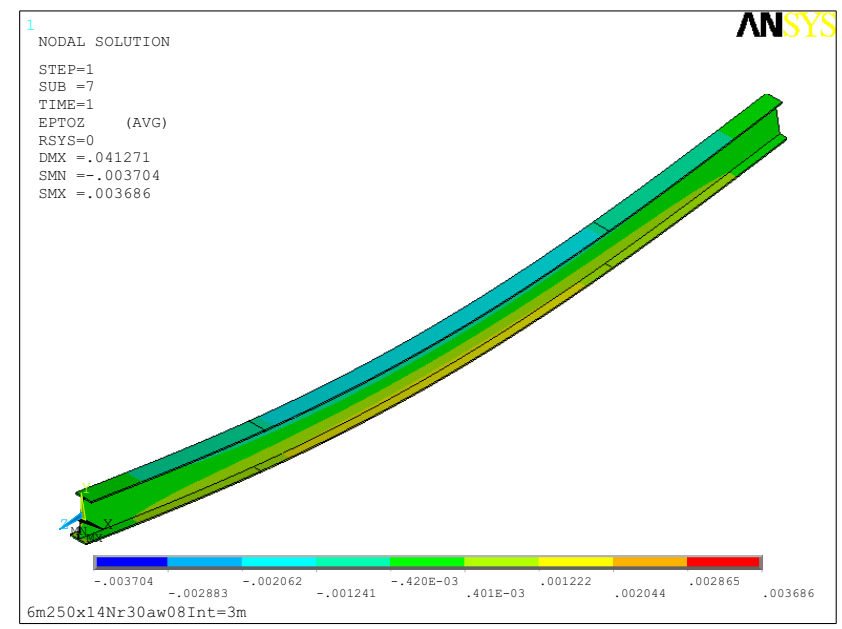

of the above mentioned elastic-plastic behavior of bisteel beam. Plastic penetration occurs in the middle of the beam and spread to the edges as the load increases (Figure 8).

Within the validity of the model, comparing the analytical solutions with the FEM solutions, the results of the numerical experiment within the $3 \%$ error coincided with the analytical result of the midspan deflection of HBB.

Based on the numerical results obtained, it can be stated that the proposed analytical model (13-24) can be applied to the stiffness analysis of simply supported bisteel I-section beams, under limited plastic penetration and limited length of the flange inclusions, approximately $l_{\text {inc }} \leq 0.6 l$. The model analytically describes the decrease in stiffness as a result of the plastic penetration.

\section{Conclusions}

The analytical model for estimating stiffness of uniformly loaded simply supported hybrid bisteel I-section beams with HSS flange inclusions has been proposed. The application of analytical model is restricted by length of inclusions approximately $l_{\text {inc }} \leq 0.6$ which is limited by the average inhomogeneity ratio $s \leq 1.6$. The results obtained in previous research performed by author shows, that for longer HSS inclusion (higher inhomogeneity ratios $s>1.6$ ) the yielding starts to split into two regions neighboring to the supports, and the application of this model needs to be refined.

The influence of strain hardening, is significant for the stiffness analysis. Strain hardening effect reduces the deflection by about 4 times compared to the perfect plasticity. While the yielding of the web with elastic flanges, reduces the stiffness up to 1.9 times with respect to monosteel beams. The additional yielding of flanges leads to plastic mechanism, while the plastic hinge is coming. The application of HSS inclusion in case perfectly elastic state of the I-section HBB, increase the deflection insignificantly (up to $10 \%$ ).

b)

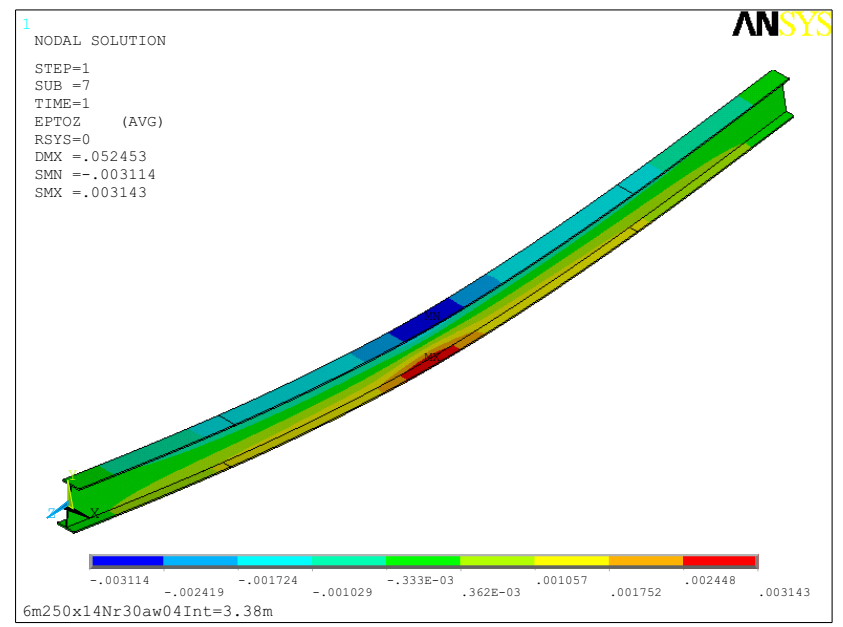

Figure 8. The deformed shape of the I section HBB, when the plastic penetration occurs only in the wall (a) and when both the wall and the HSS flanges flow (b) 
Within the validity of the model, comparing the analytical solutions with the FEM solutions, the results of the numerical experiment within the $3 \%$ error coincided with the analytical result of the stiffness parameters of hybrid bisteel beam.

After simple transformations, the model proposed can be easily applied to the evaluation of stiffness of otherwise loaded and supported hybrid bisteel beams.

\section{Acknowledgements}

The author is grateful to R. Kačianauskas, for his valuable advice during research.

\section{Funding}

Author declare that this research was not supported by any funding or grand-award bodies.

\section{References}

Alekseytsev, A.V., \& Al Ali, M. (2018). Optimization of hybrid I-beams using modified particle swarm method. Magazine of Civil Engineering, 83(7), 175-185.

ANSYS. (2019). Theory Reference, Release 19. SAS IP, Inc. (C)

Belenia, E. I. Streletskiy, N. N., Vegernikov, G. S., Klepikov, L. V., \& Moratshevskiy, T. N. (1986). Steel structures. Stroyizdat (in Russian).

Bhat, R. A., \& Gupta, L. M. (2021). Behaviour of hybrid steel beams with closely spaced web openings. Asian Journal of Civil Engineering, 22, 93-100.

https://doi.org/10.1007/s42107-020-00300-9

Dowling, P. J., \& Burgan, B. A. (1998). Steel structures in the New Millennium. Journal of Construction Steel Research, 46(1-3). https://doi.org/10.1016/S0143-974X(98)00162-X

Earls, C. J. (1999). On the inelastic failure of high strength steel Isection shaped beams. Journal of Constructional Steel Research, 49(1), 1-24. https://doi.org/10.1016/S0143-974X(98)00204-1

Elamary, A.S., Alharthi, Y., Abdalla, O., Alqurashi, M., \& Sharaky, I. A. (2021). Failure mechanism of hybridsteel beams with trape-zoidal corrugated-web non-welded inclined folds. Materials, 14(6), 1424. https://doi.org/10.3390/ma14061424

European Committee for Standardization. (2005). Eurocode 3. Design of steel structures. Part 1-5 Plated structural elements.

Gorev, V. V., Uvarov, B. J., Filippov, V. V., Beliy, G. I., Val, V. N., Yendjievskiy. L. V., Krylov. I. I., Olkov. Y. I., \& Saburov. V. F. (1997). Steel structures: Vol. 1. Elements of steel structures. Vysshaya shkola. (in Russian).

Ghadami, A., \& Broujerdian, V. (2019). Flexure-shear interaction in hybrid steel I-girders at ambient and elevated temperatures. Advances in Structural Engineering, 22(6). https://doi.org/10.1177/1369433218817893

Jaras, A., \& Kačianauskas, R. (2001). Elastic-Plastic Analysis of Bisteel I-Section Beams, Statyba, 7(2), 122-130 (in Lithuanian). https://doi.org/10.1080/13921525.2001.10531713

Jaras, A., \& Kačianauskas, R., (2002). The investigation of load carrying capacity of elastic-plastic strain hardening bisteel Isection. Journal of Civil Engineering and Management, 8(1), 34-41. https://doi.org/10.1080/13923730.2002.10531247

Ju, H., Lee, S.-J., Choi, S.-M., Kim, J. R., \& Lee, D. (2020). Applicability of hybrid built-up wide flange steel beams. Metals, 10(5), 567. https://doi.org/10.3390/met10050567
Kvedaras, A. K., Kudzys, A., \& Vaitkevičius, V. (1998). Efficient future strategies for constructing with steel in Lithuania. Journal of Constructional Steel Research, 46(1-3), 389-391. https://doi.org/10.1016/S0143-974X(98)80054-0

LR Aplinkos ministerija. (2005). Statybos techninis reglamentas STR-2.05.05:2005. Plieniniu konstrukciju projektavimas (in Lithuanian).

Owens, G., \& Wood. A. (1998). Worldwide use of steel in construction: Strategies for growth. Journal of Constructional Steel Research, 46(1-3), 422. https://doi.org/10.1016/S0143-974X(98)00161-8

Shokouhian, M., \& Shi, Y. (2015). Flexural strength of hybrid steel I-beams based on slenderness. Engineering Structures, 93, 114-128. https://doi.org/10.1016/j.engstruct.2015.03.029

The handbook of steel structures (at SNiP II-23-81*) (1989). CTIP Gosstroy, Moscow (in Russian).

Tshernov, N. L., Sherbakin, V. C., \& Tarasenko, V. L. (1992). Strength of bending elements under limited plastic strain. Improvement of the welded steel structures. Naukova dumka (in Russian).

Veljkovic, M., \& Johansson, B. (2004). Design of hybrid steel girders. Journal of Constructional Steel Research, 60, 535-547. https://doi.org/10.1016/S0143-974X(03)00128-7 
